\title{
A Comparative Study of Electrolyte Flow and Slime Particle Transport in a Newly Designed Copper Electrolytic Cell and a Laboratory-Scale Conventional Electrolytic Cell
}

\author{
WEIZHI ZENG®i) ${ }^{1,3}$ SHIJIE WANG, ${ }^{2}$ and MICHAEL L. FREE ${ }^{1}$ \\ 1.-Department of Metallurgical Engineering, University of Utah, Salt Lake City, UT 84112, USA. \\ 2.-Rio Tinto Kennecott Utah Copper, Magna, UT 84044, USA. 3.—e-mail: weizhi.zeng@utah.edu
}

An innovative copper electrolytic cell was designed with its inlet at the cell top and its outlet near the cell bottom, in opposite to conventional electrolytic cells. It was modeled in COMSOL Multiphysics to simulate copper electrorefining process. Unlike conventional electrorefining cells, downward electrolyte flows are more dominant in the fluid flow field in this cell, which leads to faster settlement of slime particles and less contamination to the cathode. Copper concentration profiles, electrolyte flow velocity field, slime particle movements, and slime particle distributions were obtained as simulation results, which were compared with those in a laboratory-scale conventional electrolytic cell. Advantages of the newly designed electrolytic cell were found: copper ions are distributed more uniformly in the cell with a thinner diffusion layer near the cathode; stronger convection exists in the inter-electrode domain with dominant downward flows; and slime particles have larger possibilities to settle down and are less likely to reach the cathode.

\section{INTRODUCTION}

Electrorefining is widely used to refine non-ferrous metals such as copper, zinc, etc. as a final step to meet purity requirements. For copper in sulfide minerals such as chalcopyrite, it is usually processed by pyrometallurgical methods first through smelting, converting, and fire refining. The resulting copper anodes have purities larger than 99\% and are further refined by electrochemical methods to purities higher than $99.99 \%$, which is the minimum requirement for subsequent processes to produce copper wires and rods. ${ }^{1,2}$ As a result, it is critical to maintain high cathode copper purity in electrorefining.

During electrorefining, anode copper dissolves and becomes cupric ions. Impurities in solid solutions also dissolve, but impurities in inclusions as second phases in the grain boundaries may not dissolve depending on their solubilities in sulfuric acid $^{3-5}$ Unless adhered to the anode, refractory inclusions are released to the solution as slime particles when the surrounding copper dissolves. As a result, two types of impurities exist in the electrolyte and impose potential influence on the purity of cathode: impurity ions and slime particles. $^{6-8}$ Due to their much lower concentrations in the solution, impurity ions such as arsenic, bismuth, and antimony have equilibrium potentials distant from that of copper, which makes them less likely to deposit electrochemically on the cathode. On the other hand, slime particles, especially small and light ones, can be carried by electrolyte flow in electrorefining cells and transported to the domain near the cathode, where they can get entrapped in the cathodic deposit. ${ }^{9,10}$

Thus, electrolyte flows in electrolytic cells, especially in the inter-electrode domains, are significant and need to be well controlled. Since upward flow can keep slime particles in suspension and exert potential harm to the cathode, downward flow would be favored along both the anode and the cathode as it facilitates the settlement of slime particles. ${ }^{9-11}$ Conventional electrorefining cells generally have inlets at positions near the cell bottom and outlets at the cell top. This design exerts upward flows in the cell and, as a matter of fact, the inlet flow under the design has less effect on the 
flow fields at the inter-electrode domains than the natural convection. Due to electrolyte density gradients (the electrolyte becomes heavier and heavier when it flows near the anode and becomes lighter and lighter when it flows near the cathode), a looping flow pattern (downward flow along the anode and upward flow along the cathode) is developed within each inter-electrode domain. ${ }^{9,10,12-17}$

Furthermore, conventional electrolytic cells usually have problems such as low limiting current density and copper depletion zone near the cathode. ${ }^{6,18,19}$ With poor convection, the diffusion boundary layer at the cathode is thick and copper ions are not transported efficiently in the bulk solution. These lead to poor diffusion rates and low limiting current densities, which make it difficult to operate copper electrodeposition at high current densities and low electrolyte copper concentrations especially in copper electrowinning.

Consequently, the geometry and configuration of electrolytic cells should be re-designed to exert stronger forced convection in a downward direction in the inter-electrode domain. Several innovative electrolytic cells have been developed, with Mettop and DBSA cells as the representatives. ${ }^{20,21}$ They are featured with inlets and outlets at side positions. Therefore, electrolyte from the inlet flows directly into the inter-electrode domain, which exerts strong convection, brings about uniform distribution of copper ions, and effectively reduces the diffusion boundary layer thickness. Thus, copper electrodeposition can occur at higher current densities with lower copper concentrations. In addition, the DBSA cells have inlets at top positions and outlets at lower positions, which leads to strong forced downward flows that help settle released slime particles in copper electrorefining. However, no data or detailed information of these innovative electrolytic cells have been revealed, which does not allow further studies on the geometry and configuration changes of copper electrolytic cells.

In this paper, copper electrorefining in a newly designed electrolytic cell was simulated using Comsol Multiphysics based on finite element method. This cell has its inlet at the top and its outlet at a lower position, which is opposite to a laboratoryscale conventional cell that has been previously modeled. ${ }^{9}$ Also, the inlets and outlets are closer to the inter-electrode domain, and there is more space under the electrodes in the newly designed cell. Note that the laboratory-scale conventional cell is not a perfect representative of real industrial conventional electrolytic cells due to laboratory restrictions. Nevertheless, we can still study the effects of different cell geometries and configurations by comparing these two cells. Therefore, the simulation results of cupric ion transfer, electrolyte flow field, and slime particle movement and distribution in the front of the cathode in both the newly designed cell and the laboratory-scale conventional cell are presented and compared.

\section{MODEL DESCRIPTION}

\section{Governing Equations}

Electrodeposition and fluid flow were coupled in the model, solving for the electrolyte potential $\Phi_{l}$, the current density distribution $i_{l}$, the concentrations of various species $c_{i}$, and the fluid velocity field $v^{22-24}$.

The electrolyte potential $\Phi_{l}$ and the electrolyte current density $\boldsymbol{i}_{l}$ are governed by Eqs. 1 and 2:

$$
\begin{gathered}
\boldsymbol{i}_{\boldsymbol{l}}=-F^{2} \nabla \Phi_{l} \sum_{i} z_{i}^{2} u_{i} c_{i}-F \sum_{i} z_{i} D_{i} \nabla c_{i} \\
\nabla \cdot \boldsymbol{i}_{\boldsymbol{l}}=0
\end{gathered}
$$

where $F$ is Faraday's constant, $-\nabla \Phi_{l}$ is an electric field, $\nabla c_{i}$ is a concentration gradient, and $z_{i}, u_{i}, c_{i}, D_{i}$ are the charge, mobility, concentration, and diffusivity of species $i{ }^{24}$

The electrode potential $\Phi_{s}$ and current density $i_{s}$ are governed by Eqs. 3 and 4:

$$
\begin{gathered}
i_{s}=-\sigma_{s} \nabla \Phi_{s} \\
\nabla \cdot \boldsymbol{i}_{s}=0
\end{gathered}
$$

where $\sigma_{s}$ is the conductivity of the electrode and $\nabla \Phi_{s}$ is an electric field. Equation (4) describes the conservation of current on the electrodes. The electric potentials on the anode and the cathode were assumed to be constant and the electric potential of the cathode was defined as $0 \mathrm{~V}$ (a reference potential).

The current densities at the electrode-electrolyte interface are governed by Eq. 5-8. Parameters in Eq. 5 such as $i_{0}, \alpha_{a}$, and $\alpha_{c}$ were assumed to have typical values in copper electrorefining ${ }^{25}$ and are specified in Table I.

$$
\begin{gathered}
i_{\mathrm{loc}}=i_{0}\left[\frac{C_{\mathrm{R}, \mathrm{S}}}{C_{\mathrm{R}, \mathrm{B}}} \exp \left(\frac{\alpha_{a} z F}{\mathrm{RT}} \eta\right)-\frac{C_{\mathrm{O}, \mathrm{S}}}{C_{\mathrm{O}, \mathrm{B}}} \exp \left(-\frac{\alpha_{c} z F}{\mathrm{RT}} \eta\right)\right] \\
\eta=\Phi_{S}-\Phi_{l}-\Delta \Phi_{\mathrm{eq}} \\
\boldsymbol{i}_{\boldsymbol{l}} \cdot \boldsymbol{n}=\mathrm{i}_{\mathrm{loc}} \\
\int_{\text {Anode surface }} \boldsymbol{i}_{\boldsymbol{l}} \cdot \boldsymbol{n} \mathrm{d} S=\int_{\text {Cathode surface }} \boldsymbol{i}_{\text {Cathode surface }} \mathrm{d} \cdot \boldsymbol{n} \mathrm{d} S=\mathrm{i}_{\text {Average }}
\end{gathered}
$$


where $i_{\text {loc }}$ is the local current density at the electrode-electrolyte interface, $C$ is the copper concentration, the subscripts $R, O, S, B$ represent reductant, oxidant, surface, and bulk, respectively, $\eta$ is the local overpotential at the interface, $\Delta \Phi_{\text {eq }}$ is the equilibrium potential difference, $i_{l}$ is the current density in the electrolyte at the interface, $\boldsymbol{n}$ is the unit normal vector to the electrode surface, and $i_{\text {average }}$ is the average current density on cathode. ${ }^{6,24}$

The flow velocity vector $v$ in Eq. 9 connects current density distribution with electrolyte flow velocity field:

$$
N_{i}=-z_{i} u_{i} F c_{i} \nabla \Phi_{l}-D_{i} \nabla c_{i}+c_{i} v
$$

The species concentration $c_{i}$ can be solved with the addition of Eq. 10 that describes materials balance:

$$
\frac{\partial c_{i}}{\partial \mathrm{t}}+\nabla \cdot \boldsymbol{N}_{\boldsymbol{i}}=0
$$

A variable density and viscosity flow, dependent on temperature and concentrations of cupric ions and acid, was assumed, which is governed by the continuity and momentum equations. ${ }^{24,26}$ Equation 13 and 14 are based on the experimental data from Price and Davenport. ${ }^{27}$

$$
\begin{gathered}
\frac{\partial \rho}{\partial \mathrm{t}}+\nabla \cdot(\rho \boldsymbol{v})=0 \\
\rho \frac{\partial \boldsymbol{v}}{\partial \mathrm{t}}+\rho \boldsymbol{v} \cdot \nabla \boldsymbol{v}=-\nabla p+\nabla \cdot\left(\mu\left(\nabla \boldsymbol{v}+(\nabla \boldsymbol{v})^{\mathrm{T}}\right)\right. \\
\left.-\frac{2}{3} \mu(\nabla \cdot \boldsymbol{v}) \mathrm{I}\right)+\boldsymbol{F} \\
\rho\left[\mathrm{kg} / \mathrm{m}^{3}\right]=1018.56+0.1512[\mathrm{Cu}] \\
+0.54 C_{H 2 S O 4}-0.59(T-273.15) \\
\mu(\mathrm{Pa} \cdot \mathrm{s})=\frac{1}{1000}(-1989.46+0.010353(0.06355[\mathrm{Cu}]) \\
\left.+0.0014685 C_{\mathrm{H} 2 \mathrm{SO} 4}+1983.72 \exp \left(\frac{1}{T}\right)\right)
\end{gathered}
$$

where $\rho$ is the electrolyte density, $\mu$ is the dynamic viscosity, $\boldsymbol{v}$ is the electrolyte velocity, $p$ is the pressure, $\boldsymbol{I}$ is the identity tensor, $\boldsymbol{F}$ is the body force per unit volume, [Cu] is the local copper concentration in $\mathrm{mol} / \mathrm{m}^{3}, C_{\mathrm{H} 2 \mathrm{SO} 4}$ is the initial $\mathrm{H}_{2} \mathrm{SO}_{4}$ concentration in $\mathrm{Kg} / \mathrm{m}^{3}$, and $T$ is the electrolyte temperature in $K$.

The slime particle transport in the electrolyte flow was simulated by applying the steady-state solution of the fluid flow field. The effects of slime particles on the electrolyte flow were neglected due to their small masses.

The motion of a slime particle in the fluid flow is governed by Newton's second law:

$$
m_{\mathrm{p}} \frac{\mathrm{d}^{2} \boldsymbol{x}}{\mathrm{d} t^{2}}=\boldsymbol{F}\left(\mathrm{t}, \boldsymbol{x}, \frac{\mathrm{d} \boldsymbol{x}}{\mathrm{d} t}\right)
$$

where $m_{\mathrm{p}}$ is the particle mass, $\boldsymbol{x}$ is the particle position, and $\boldsymbol{F}$ is the sum of forces acting on the slime particle ${ }^{24}$.

The drag force on a slime particle is determined by Stokes' law and the slime particle is also subject to gravity and buoyancy forces on the vertical direction:

$$
\begin{gathered}
\boldsymbol{F}_{\boldsymbol{d}}=\frac{18 \mu \mathrm{m}_{\mathrm{p}}}{\rho_{\mathrm{p}} \mathrm{d}_{\mathrm{p}}^{2}}\left(\boldsymbol{v}-\boldsymbol{v}_{\boldsymbol{p}}\right) \\
\boldsymbol{F}_{z}=-\left(\rho_{\mathrm{p}}-(\rho)\right) \mathrm{g} V_{\mathrm{p}}
\end{gathered}
$$

where $\boldsymbol{F}_{\boldsymbol{d}}$ is the drag force vector, $F_{z}$ is the sum of forces in the $z$ direction, $v$ is the fluid velocity, and $\mathrm{m}_{\mathrm{p}}, \rho_{\mathrm{p}}, d_{\mathrm{p}}, v_{p}, V_{\mathrm{p}}$ are the mass, density, diameter,

\begin{tabular}{|c|c|c|c|}
\hline Description & Value & Description & Value \\
\hline Exchange current density & $0.2\left(\mathrm{~A} / \mathrm{m}^{2}\right)$ & Anode symmetry factor & 1.5 \\
\hline Temperature & $323.15(\mathrm{~K})$ & Cathode symmetry factor & 0.5 \\
\hline Concentration of $\mathrm{H}_{2} \mathrm{SO}_{4}$ & $180(\mathrm{~g} / \mathrm{l})$ & Initial concentration of cupric ion & $45(\mathrm{~g} / \mathrm{l})$ \\
\hline Current density (average) & $375\left(\mathrm{~A} / \mathrm{m}^{2}\right)$ & Inlet/outlet flow rate & $11(\mathrm{ml} / \mathrm{min})$ \\
\hline Impurity particle diameter & $14.5 \mathrm{E}-6(\mathrm{~m})$ & Impurity particle density & $4200\left(\mathrm{~kg} / \mathrm{m}^{3}\right)$ \\
\hline
\end{tabular}
velocity, and volume of the slime particle, respectively. ${ }^{24}$

\section{Boundary Conditions}

Insulation boundary condition (applied on faces other than the electrode faces):

$$
-\boldsymbol{n} \cdot \boldsymbol{i}=0
$$

No flux boundary condition (applied on faces other than the electrode faces, the inlet faces, and the outlet face):

Table I. Main parameters and boundary conditions applied in the simulations 


$$
-\boldsymbol{n} \cdot \boldsymbol{N}_{\boldsymbol{i}}=0
$$

Slip wall boundary condition (applied on the top face of the cell $)^{24}$ :

$$
\boldsymbol{v} \cdot \boldsymbol{n}=0
$$

$$
\mu\left(\nabla \boldsymbol{v}+(\nabla \boldsymbol{v})^{\mathrm{T}}\right) \boldsymbol{n}-\left(\mu\left(\nabla \boldsymbol{v}+(\nabla \boldsymbol{v})^{\mathrm{T}}\right) \boldsymbol{n} \cdot \boldsymbol{n}\right) \boldsymbol{n}=0
$$

No slip wall boundary condition (applied on all other (aces $)^{24}$ :

$$
\boldsymbol{v}=0
$$

In Eqs. 18-22, $\boldsymbol{n}$ is the unit normal vector to the face, and $\boldsymbol{i}$ is the current density, $\boldsymbol{N}_{\boldsymbol{i}}$ is the flux density of species $i, v$ is the velocity vector of the electrolyte flow, $\mu$ is the dynamic viscosity, $p_{\mathrm{o}}$ is the pressure at the outlet, and $I$ is the identity tensor.

The inlet face and the outlet face were defined to have the flow rate presented in Table I and the inflow electrolyte has the same species concentrations as the initial cell electrolyte, as shown in Table I.

The electrolyte conductivity ${ }^{23}$, and the diffusivity $^{28}$ and mobility of species, are determined by the following equations:

$$
\begin{aligned}
& \sigma_{l}=F^{2} \sum_{i=1}^{n} z_{i}^{2} u_{i} c_{i} \\
& \log \left(D\left[\mathrm{~cm}^{2} / \mathrm{s}\right]\right)=-0.676-0.481 \log C_{\mathrm{H} 2 \mathrm{SO} 4} \\
& -0.156 \log (0.06355[\mathrm{Cu}]) \\
& +0.9885 \frac{-8340.61}{8.314 T} \\
& u_{i}=\frac{D_{i}}{\mathrm{RT}}
\end{aligned}
$$

A body force per unit volume caused by gravity was applied on the fluid:

$$
\begin{aligned}
F_{z}\left[\mathrm{~N} / \mathrm{m}^{3}\right]= & -\rho \mathrm{g}=-\mathrm{g}(1018.56+0.1512[\mathrm{Cu}] \\
& \left.+0.54 C_{\mathrm{H}_{2} \mathrm{SO}_{4}}-0.59(T-273.15)\right)
\end{aligned}
$$

where $F_{z}$ is the gravity body force in the $z$ direction, $g$ is the gravity acceleration, and $\rho$ is the density of the electrolyte.

Ten thousands of slime particles were uniformly released from the inlet face every $500 \mathrm{~s}$ from $t=0 \mathrm{~s}$. Their initial velocities are equal to the inflow electrolyte velocities. Main parameters and boundary conditions are presented in Table I.

\section{Geometry}

Figure 1a shows the geometry of the newly designed electrolytic cell. This cell is $0.075 \mathrm{~m}$ in length, $0.1 \mathrm{~m}$ in width, and $0.12 \mathrm{~m}$ in height. It
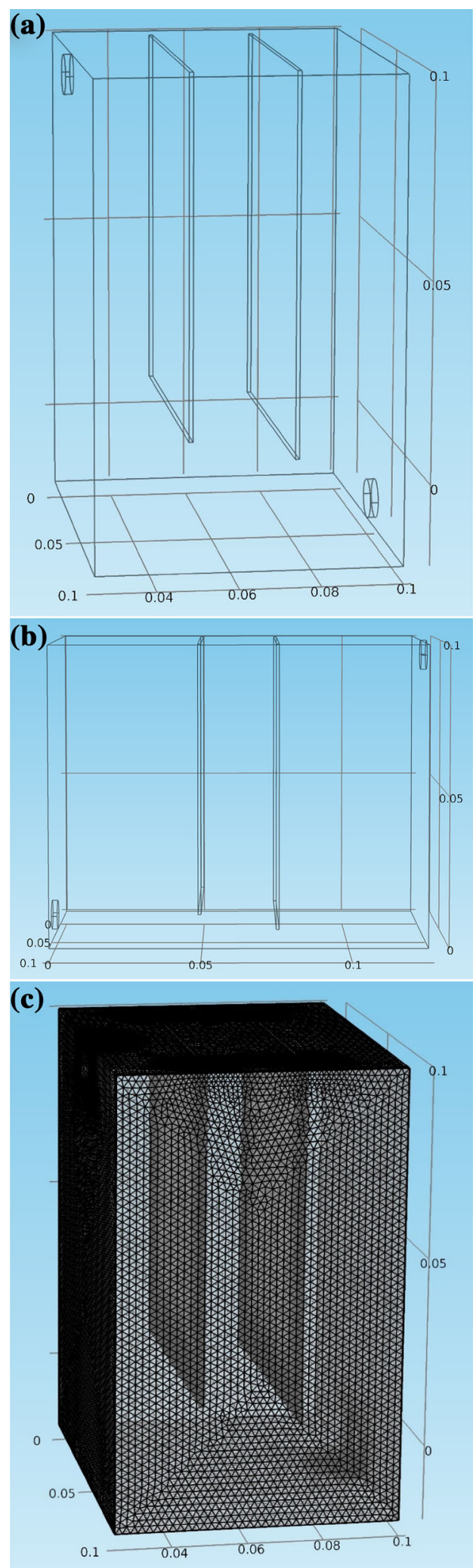

Fig. 1. (a) The geometry of the newly designed copper electrolytic cell in the model. (b) The geometry of the laboratory-scale conventional electrolytic cell in the model. ${ }^{9}$ (c) Cell meshes in the newly designed copper electrolytic cell in the model. 
has one pair of anode and cathode. The anode is $0.08 \mathrm{~m}$ in width, $0.09 \mathrm{~m}$ in height, and $0.001 \mathrm{~m}$ in thickness, and the cathode is $0.08 \mathrm{~m}$ in width, $0.095 \mathrm{~m}$ in height, and $0.001 \mathrm{~m}$ in thickness. The gap between the anode and the cathode is $0.025 \mathrm{~m}$. The inflow and outflow pipes are both $0.005 \mathrm{~m}$ in radius and $0.002 \mathrm{~m}$ in length. The axes of the pipes are on the $y$ direction and their coordinates are: $x=0.05 \mathrm{~m}$ and $z=0.115 / 0.005 \mathrm{~m}$. Note that only the front side faces of the anode and the cathode were defined to have electrode reactions $\left(\mathrm{Cu}(\mathrm{s}) \leftrightarrow \mathrm{Cu}_{(\mathrm{aq})}^{2+}+2 \mathrm{e}^{-}\right)$. As presented in Fig. 1a, the left side of the inflow pipe was defined as the inlet face, and the right side of the outflow pipe was defined as the outlet face.

Figure $1 \mathrm{~b}$ shows the laboratory-scale conventional electrolytic cell. It is $0.05 \mathrm{~m}$ larger in cell length but $0.02 \mathrm{~m}$ smaller in cell height. Most importantly, its inlet is located near the cell bottom and its outlet is located at the cell top. This opposite positioning of the inlet and outlet can have significant effects on the resulting electrolyte flow field. The dimensions of the electrodes in the laboratoryscale conventional cell are the same as those in the newly designed cell.

\section{Mesh}

The domain of the newly designed electrolytic cell was discretized into tetrahedral mesh elements in the model as shown in Fig. 1c. The domain meshes in the cell have a maximum element size, a minimum element size, and a maximum element growth rate of $0.0053 \mathrm{~m}, 0.001 \mathrm{~m}$, and $1.13 \mathrm{~m}$, respectively. Triangular boundary elements formed structured layers on surface boundaries. Finer boundary layer elements and the domain tetrahedral mesh elements were integrated in the models. Two layers of boundary elements were formed on every surface boundary. The first boundary layer is $0.00129 \mathrm{~m}$ in thickness and the second boundary layer is $0.00155 \mathrm{~m}$. In particular, surface boundaries of the front faces of the electrodes have eight layers of triangular elements. The first layer is $0.0001 \mathrm{~m}$ in thickness and the thicknesses of other layers are determined by a boundary layer stretching factor of 1.2 , which means that the layer thickness gradually increases by $20 \%$ from the first layer. The triangular boundary elements have a maximum element size, a minimum element size, and a maximum element growth rate of $0.0023 \mathrm{~m}, 0.00015 \mathrm{~m}$, and $1.08 \mathrm{~m}$, respectively. The geometrical edges and vertices in the cell were discretized into edge elements and vertex elements. Several mesh refinements were performed before the application of the current meshes, whose simulation results have no appreciable difference from those acquired by applying the previous lower quality meshes. The laboratory-scale conventional electrolytic cell has similar mesh sizes after mesh refinement as the newly designed electrolytic cell.

\section{RESULTS AND DISCUSSION}

It is significant to control the mass transport of different species such as cupric ions, sulfate ions, hydrogen ions, etc. in copper electrolysis. Since the electrode reactions involve only cupric ions in the cell, cupric ion transport is most significant at steady state and the transfer rates of other species are typically zero due to the counterbalance of diffusion and migration. The limiting step in copper electrodeposition is usually diffusion rather than electrochemical reaction. Therefore, the concentration distribution of cupric ions in the cell, especially around boundary layers, is significant as it indicates the efficiency of the diffusion process. The cupric ion concentration profiles in the newly designed and the conventional electrolytic cells were obtained from the simulations and are presented in Fig. 2a and b.

It can be found that cupric ions are distributed more uniformly in the newly designed electrolytic cell. The maximum copper concentration difference in the inter-electrode domain is smaller in the newly designed cell (about $730 \mathrm{~mol} / \mathrm{m}^{3}$ ) than in the laboratory-scale conventional cell (about $1180 \mathrm{~mol} / \mathrm{m}^{3}$ ). Mostly importantly, the thicknesses of the diffusion layers in front of the anode and cathode are thinner in the newly designed electrolytic cell as indicated by the widths of copper concentration gradient zones. With the smaller copper concentration difference in the newly designed cell, a thinner diffusion boundary layer is required to reach the same current density. Thinner diffusion boundary layers can provide larger copper concentration gradients and faster diffusion rates under higher current densities. Therefore, the transport of cupric ions would be more efficient in the newly designed cell with modified geometry which gives the possibility to operate copper electrorefining or electrowinning at higher current densities and lower electrolyte copper concentrations.

The fluid flow velocity field in the cell is driven by inflow/outflow and fluid density gradients between the electrodes, which are determined by copper concentration differences. The newly designed cell has different electrolyte density gradients (copper concentration differences) in the inter-electrode domain, as well as different cell geometry and different inlet/outlet configurations. As a result, its fluid flow field should be quite different from that in the laboratory-scale conventional cell, which is shown in Fig. $3 a$ and $b$.

From Fig. $3 a$ and $b$, the most significant difference in the electrolyte flow field between the newly designed electrolytic cell and the laboratory-scale conventional cell is the convection intensity, especially between the electrodes. Due to narrower and taller cell designs, the electrolyte inflow and outflow have stronger effects on the fluid flow in the newly designed cell and the convection in the inter-electrode domain becomes more intense. Because of the fluid density gradients, the electrolyte flows 

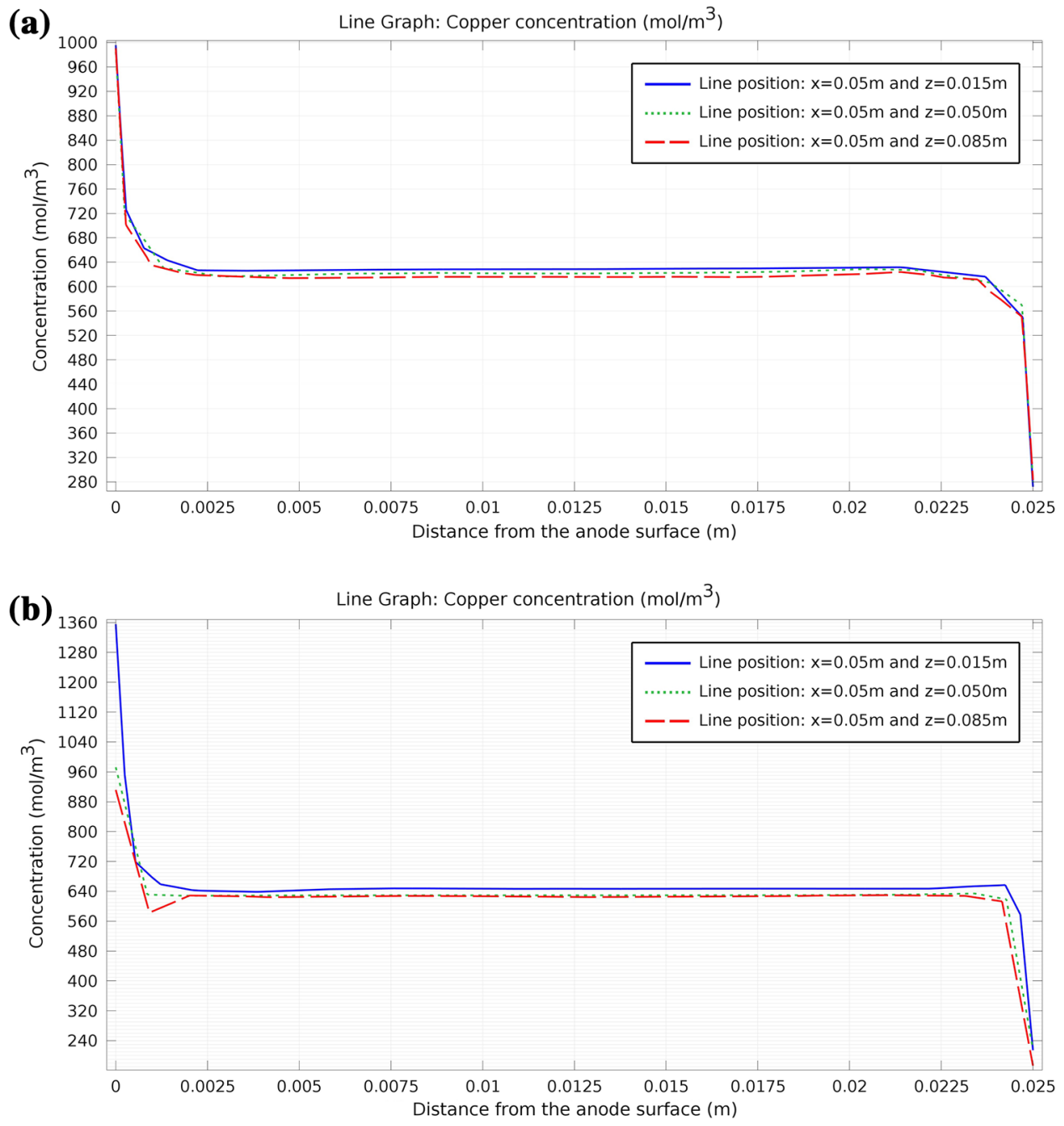

Fig. 2. (a) and (b) Cupric ion concentration profiles at different heights within the inter-electrode domain under $11 \mathrm{ml} / \mathrm{min}, 50^{\circ} \mathrm{C}$, and $375 \mathrm{~A} / \mathrm{m}^{2}$ in the newly designed electrolytic cell (a) and the laboratory-scale conventional cell (b) defined in "Geometry" section.

between the anode and the cathode in the newly designed cell still follow looping patterns, similar to those in the laboratory-scale conventional cell. In addition, the downward fluid flows below the anode in the newly designed cell are of considerabl size, resulting from the combined effects of the natural anode downward flow and the forced inlet to outlet downward flow. Most of these downward electrolyte flows turn right and flow to the outlet; the rest of them turn around and flow back up, creating more convections in the cell. These enhanced downward electrolyte flows can help settle most slime particles without affecting the purity of the cathode, though some slime particles can be re-picked up by the turn-around upward flows and re-enter the interelectrode domain. In addition, the configuration of the top inlet and the bottom outlet makes downward flows more dominant in the newly designed cell, and therefore renders more opportunities for slime particles to settle or flow out of the cell. Note that these are achieved under the same flow rate, temperature, and current density. Consequently, the newly designed cell generates a fluid flow field with advantages over that in the laboratory-scale conventional cell, which has less convections and is more dominated by upward electrolyte flows.

The magnitudes of upward/downward flows and their affecting area are shown in Fig. $4 \mathrm{a}$ and b. Along the anode, the downward flows dominate and become faster and faster as the height decreases; along the cathode, the upward flows are dominant with increasing magnitudes as the height increases. The newly designed cell has larger maximum downward flow magnitude and smaller maximum upward flow magnitude, compared with the laboratory-scale conventional cell. The middle region in the gap between the anode and the cathode is also affected by different extent in the two cells. In the newly designed electrolytic cell, the magnitudes of the upward and downward flows decrease slowly, with most of the middle region influenced. In the laboratory-scale conventional cell, the upward and 
(a)

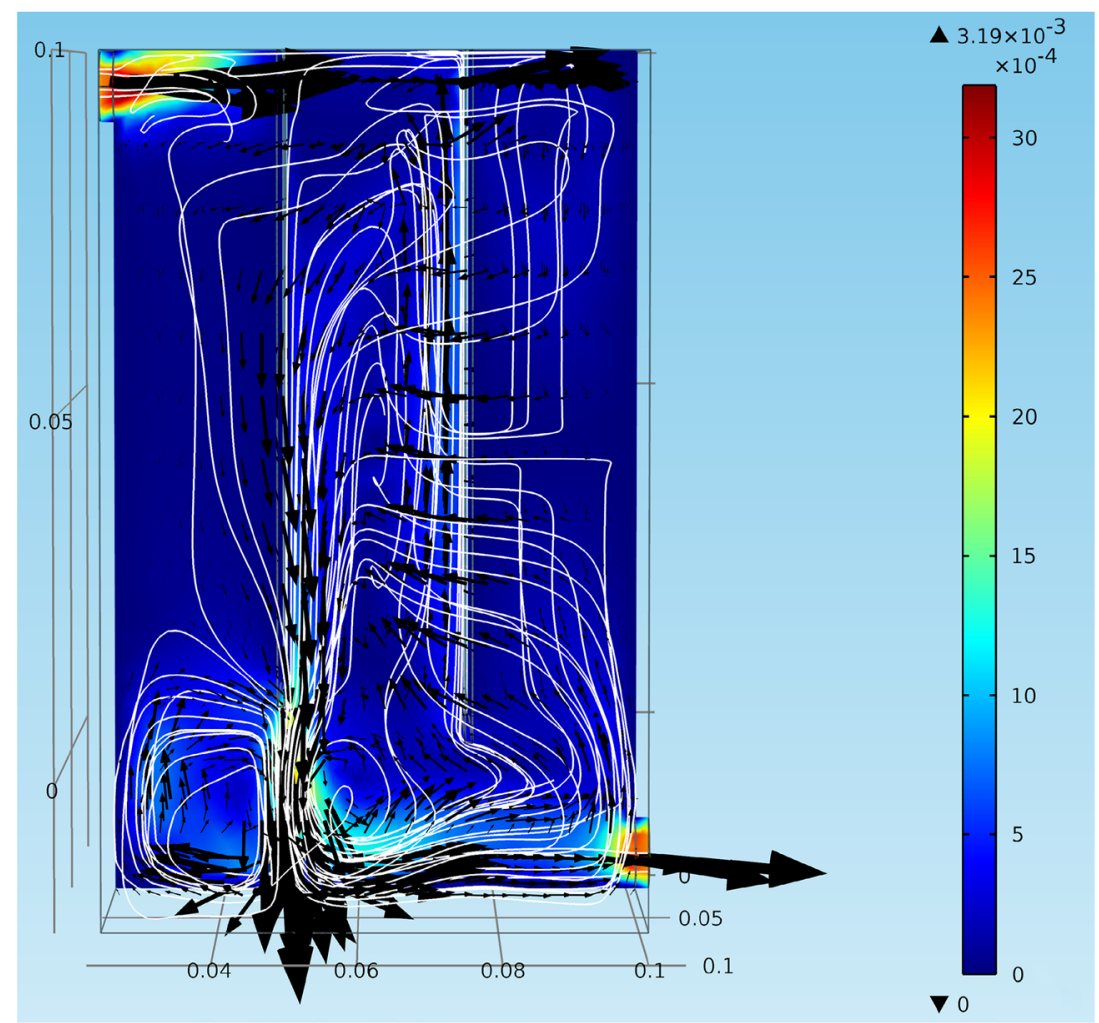

(b)

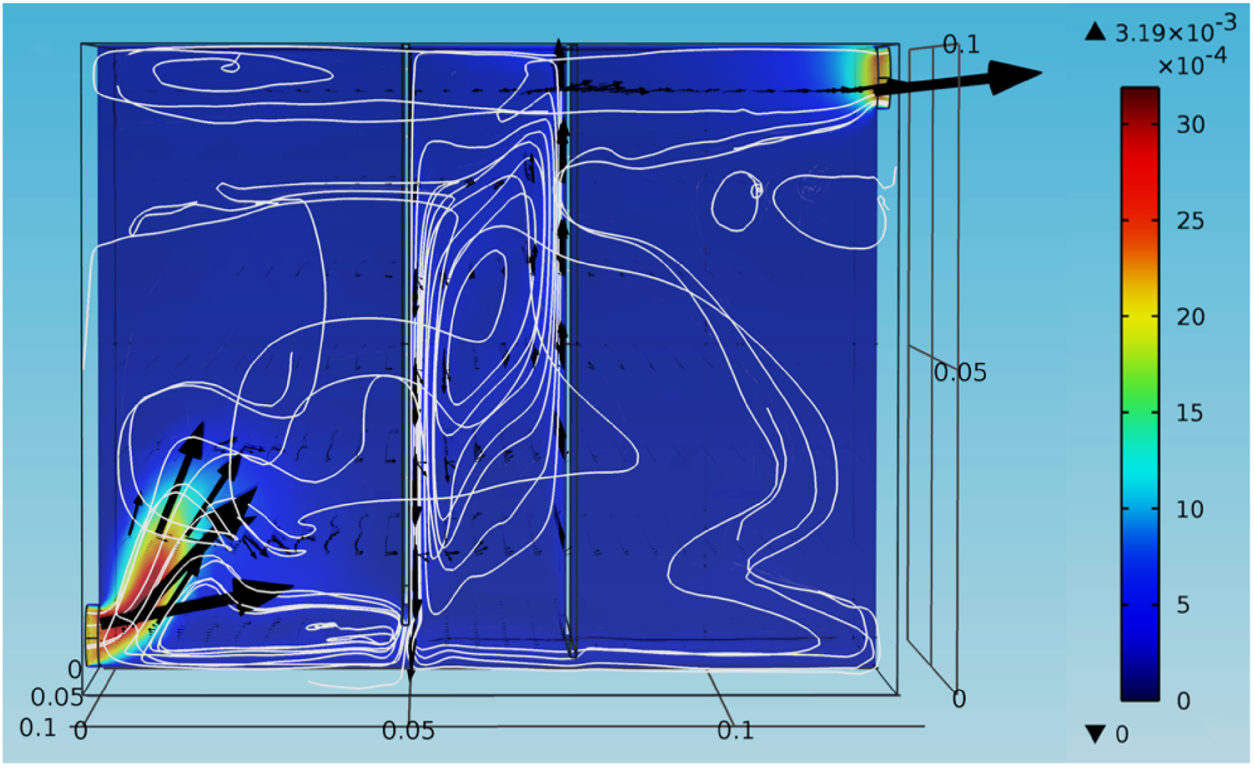

Fig. 3. (a) and (b) Electrolyte flow velocity fields under $11 \mathrm{ml} / \mathrm{min}, 50^{\circ} \mathrm{C}$, and $375 \mathrm{~A} / \mathrm{m}^{2}$ at steady state, in the newly designed electrolytic cell (a) and the laboratory-scale conventional cell (b) (the color expresses the magnitudes of flow velocities, black arrows represent velocity vectors, and white lines are streamlines).

downward flows fade fast and most of the middle region has no apparent electrolyte flow. Therefore, the convection within the inter-electrode domain becomes stronger with the geometry and configuration of the newly designed cell. More intense convection between the anode and the cathode supports copper electrolysis at higher current densities by providing effective and efficient mass transport of cupric ions.

Under different electrolyte flow velocity fields in the two cells, the slime particles entering from the inlet should have quite different movements during 

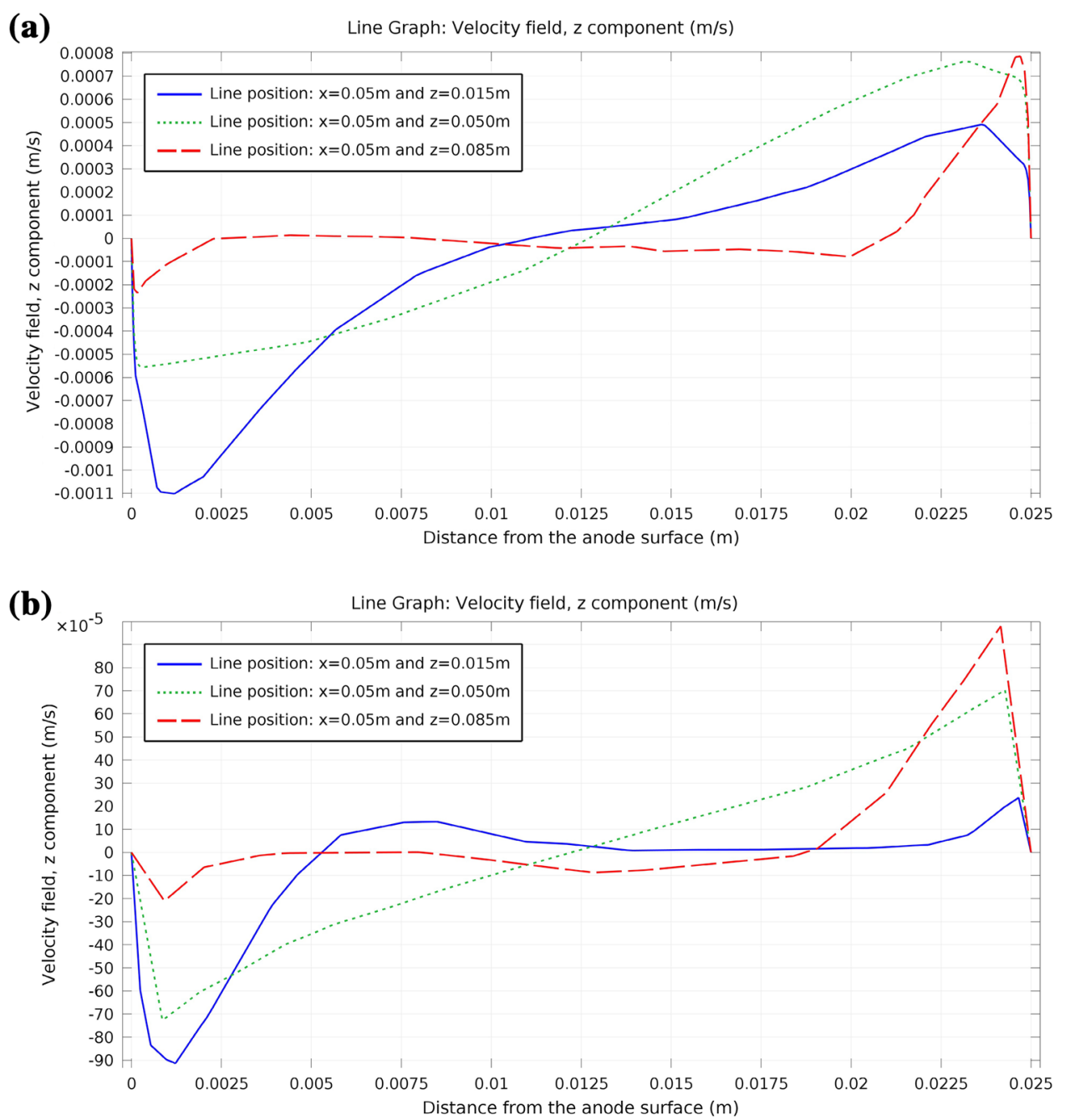

Fig. 4. (a) and (b) z-direction electrolyte flow velocity profiles at different heights within the inter-electrode domain under $11 \mathrm{ml} / \mathrm{min}, 50^{\circ} \mathrm{C}$, and $375 \mathrm{~A} / \mathrm{m}^{2}$ in the newly designed electrolytic cell (a) and the laboratory-scale conventional cell (b) defined in "Geometry" section.

copper electrorefining. In the models, tens of thousands of slime particles with specified diameters and densities, as shown in Table I, are released from the inlet face every $500 \mathrm{~s}$ in both electrolytic cells. The motions of slime particles in the cells are driven by the electrolyte flow field and their own gravities. The instantaneous positions of slime particles at four time points in the newly designed electrolytic cell and the laboratory-scale conventional cell are presented in Figs. 5a-d and $6 \mathrm{a}-\mathrm{d}$, respectively.

The motions of slime particles in both electrolytic cells can be observed accordingly and their differences can be found. Note that new groups of slime particles enter the cells at $t=0 \mathrm{~s}, 500 \mathrm{~s}, 1000 \mathrm{~s}$, $1500 \mathrm{~s}$, etc. and therefore more and more groups of particles show up in the cells as time passes. In the newly designed electrolytic cell, the slime particles flow into the cell from the inlet at the top, and most of the particles encounter the back side of the anode and move downwards. Some of the slime particles pass over the inter-electrode domain through the side gaps between the edges of electrodes and the side walls, and they also turn downward after encountering the wall. With the dominant downward flows in the cell, all these particles travel to the bottom domain of the cell. Some of the slime particles can be picked up by upward backflows under the electrodes and enter the inter-electrode domain. A significant amount of particles settled down at the bottom face of the cell or left the cell through the outlet because of the intense downward flows near the cell bottom. Particles entering the gap between the anode and the cathode were moving in loops due to the natural convection flow pattern. However, when these particles reach the bottom of the inter-electrode domain, a large portion of them fail to be re-picked up by the weak upward flows there but rather settle with the strong downward flows. Consequently, most of the slime particles in the newly designed electrolytic cell tend to settle to the bottom or flow out through the outlet, 

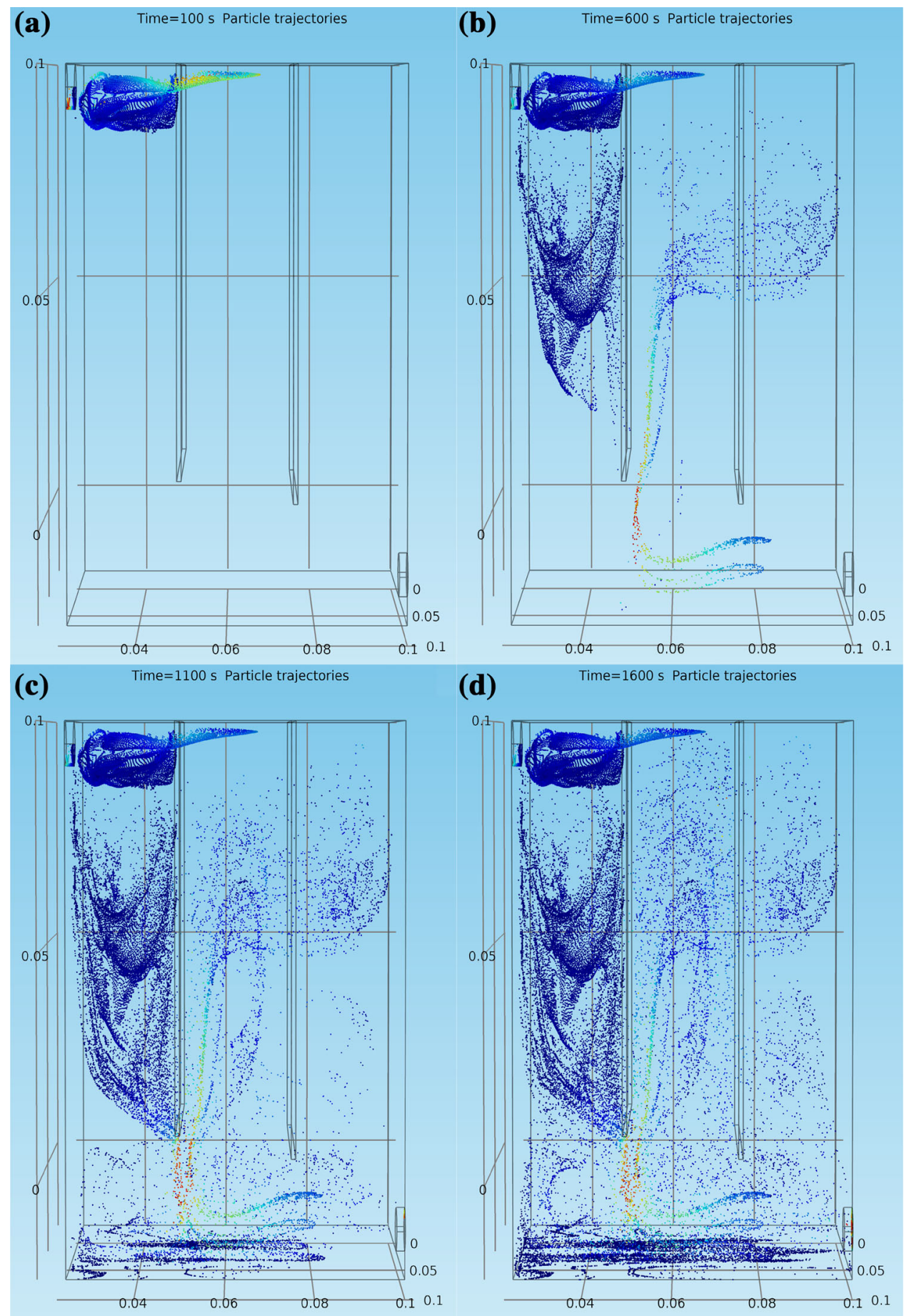

Fig. 5. (a-d) Instantaneous positions of slime particles at $t=100 \mathrm{~s}, t=600 \mathrm{~s}, t=1100 \mathrm{~s}$, and $t=1600 \mathrm{~s}$ in the newly designed copper electrolytic cell defined in "Geometry" section.

and not many slime particles have the opportunities to enter the inter-electrode domain where they may be entrapped in the cathode deposit, and even fewer particles can stay suspended in the inter-electrode domain after reaching the bottom of it.
On the other hand, a large number of slime particles in the laboratory-scale conventional cell enter the inter-electrode domain after released from the inlet, due to the relative position of the inlet to the electrodes as well as the dominant upward flows 


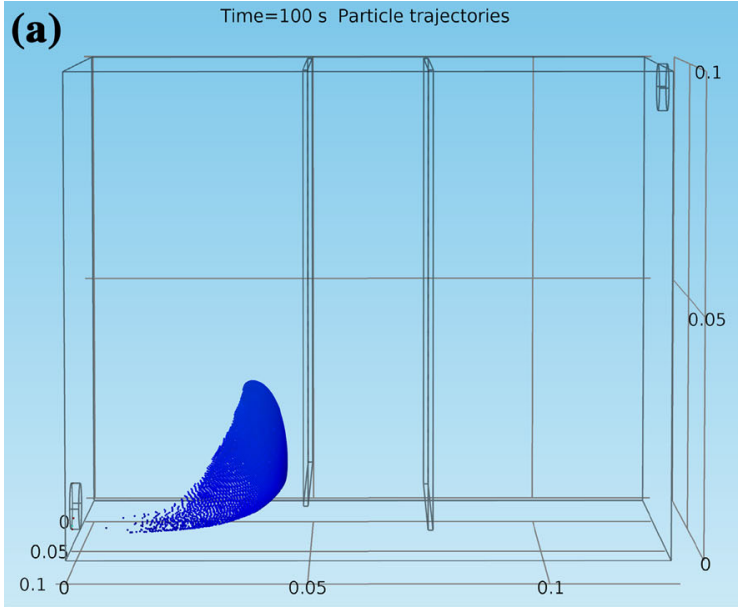

(c)

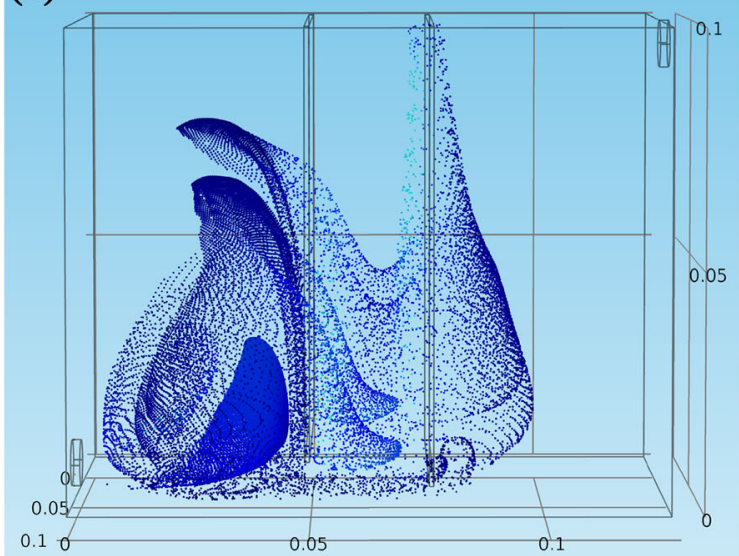

(b)

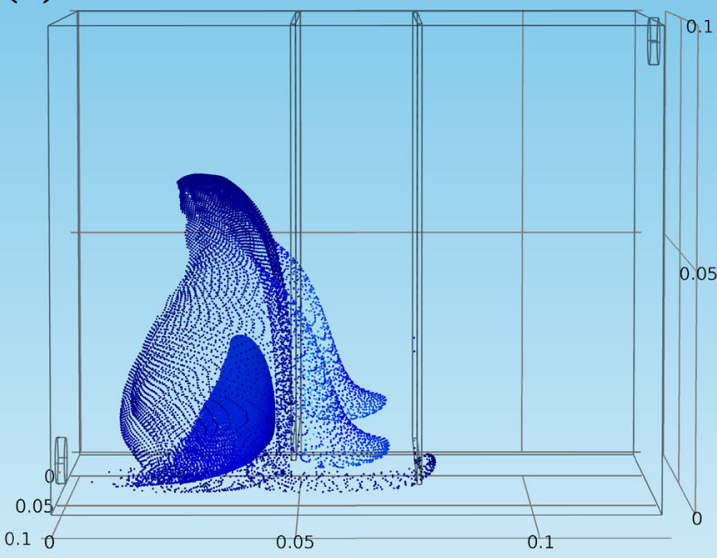

(d)



Fig. 6. (a-d) Instantaneous positions of slime particles at $t=100 \mathrm{~s}, t=600 \mathrm{~s}, t=1100 \mathrm{~s}$, and $t=1600 \mathrm{~s}$ in the laboratory-scale conventional electrolytic cell defined in "Geometry" section.

in the cell. More importantly, these particles can keep flowing in the domain and thus have more opportunities to affect the cathode purity. At the bottom of the inter-electrode domain, there are no intense downward flows and most slime particles can be re-picked up and move upwards along the cathode again. As a result, under the effects of dominant upward flows and the position of the inlet, slime particles in the laboratory-scale conventional cell are more likely to flow into the inter-electrode domain.

Therefore, slime particles released from the inlet are transported in a better way under the electrolyte flow field in the newly designed electrolytic cell, where most of them have settled to the cell bottom without affecting the cathode purity. In order to analyze the slime particle distributions in the front of the cathode, the particles on a slice $100 \mu \mathrm{m}$ from the front surface of the cathode are shown in Fig. 7a and b for both electrolytic cells.

Particles with a distance from the cathode within $100 \mu \mathrm{m}$ have large opportunities to be incorporated into the deposit, while particles with larger distances from thecathodes are less likely to co-deposit with copper. Therefore, the numbers and distributions of slime particles on this slice can reflect further slime contamination on thecathodic deposit. From Fig. $7 \mathrm{a}$ and b, some observations can be made. Firstly, many fewer slime particles are distributed in front of the cathode in the newly designed electrolytic cell than in the laboratoryscale conventional cell. Secondly, slime particles are more likely to appear in front of the corners than in front of the center of the cathode in both cells. Thus, more contamination on the cathode corners are expected. ${ }^{9}$, ${ }^{11}$ Thirdly, most slime particles are distributed at lower positions of the slice in the newly designed electrolytic cell, which should be due to the weak upward flows at the bottom of the cathode as discussed previously. Therefore, slime particles that have reached the cathode bottom in the newly designed cell are difficult to pick up, but tend to settle. In conclusion, slime particles transport in the newly designed cell is better controlled, as they are less likely to be transported to the region near the cathode but rather settle to the bottom by the dominant downward flows. 

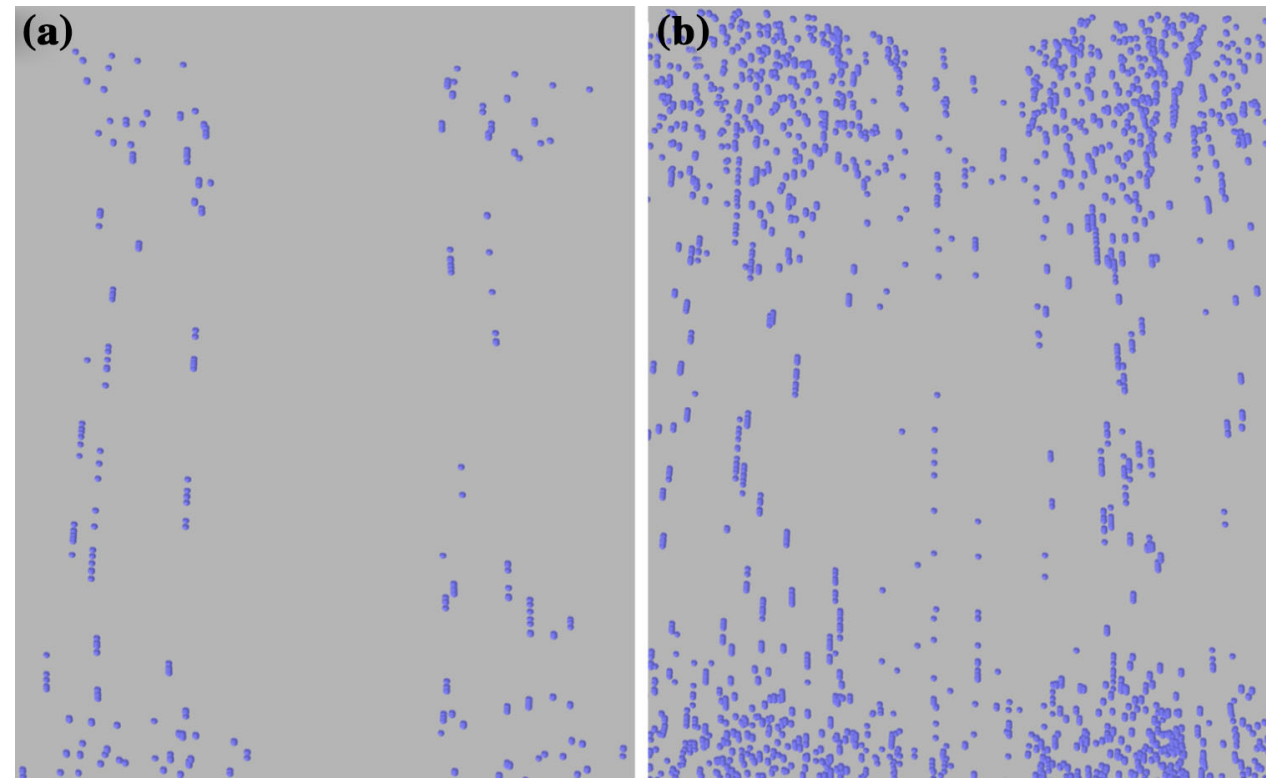

Fig. 7. (a) and (b) Slime particle distribution on a slice $100 \mu \mathrm{m}$ from the front surface of the cathode under $11 \mathrm{ml} / \mathrm{min}, 50^{\circ} \mathrm{C}$, and $375 \mathrm{~A} / \mathrm{m}^{2}$ at $t=18,000 \mathrm{~s}$, in the newly designed electrolytic cell (a) and the laboratory-scale conventional cell (b) defined in "Geometry" section.

\section{CONCLUSION}

After comparing the simulation results between the newly designed electrolytic cell and the laboratory-scale conventional electrolytic cell, features and advantages of the newly designed cell were demonstrated in cupric ion mass transfer, electrolyte flow velocity field, and slime particle movements and distributions in front of the cathode. The switching of inlet and outlet and the narrower and taller cell design combined have the following significant effects in copper electrorefining:

Firstly, the newly designed electrolytic cell has a more uniform distribution of cupric ions and thinner diffusion boundary layers than the laboratory-scale conventional cell. These lead to more efficient mass transport of cupric ions and make it possible to operate copper electrodeposition at higher current densities and lower copper concentration.

Secondly, the electrolyte flow velocity field in the newly designed electrolytic cell shows better convection within the inter-electrode domain than that in the laboratory-scale conventional cell, which can facilitate mass transfer of cupric ions. Furthermore, downward flows are more dominant in the newly designed cell and can help settle most slime particles.

Thirdly, the newly designed electrolytic cell has better control over the movements of slime particles. Slime particles released from the inlet have fewer opportunities to enter the inter-electrode domain. Even for those that are transported to the domain, they are less likely to be re-picked up when following the loop and reaching the bottom of the domain. These are due to the dominant downward flows in the newly designed electrolytic cell. As a result, it is more difficult for the slime particles in the newly designed cell to reach the cathode surface and get entrapped in the deposit. The distributions of slime particles on a slice $100 \mu \mathrm{m}$ from the front surface of the cathode also show that fewer slime particles are distributed in front of the cathode in the newly designed cell. Only a small portion of the slime particles that have reached the bottom of the cathode can be picked up by the weak upward flows along the cathode in the newly designed cell.

In conclusion, the newly designed copper electrolytic cell has advantages over the laboratoryscale conventional electrolytic cell in terms of mass transfer efficiency and slime particle control. The simulation results comparison between the two cells demonstrates that the positions of the inlet and outlet should be as close to the inter-electrode domain as possible, and the configuration of the top inlet and bottom outlet leads to more favorable fluid flow field and better slime particle control.

\section{REFERENCES}

1. M. Stelter and H. Bombach, Adv. Eng. Mater. 6, 558 (2004).

2. M. Moats and M. Free, JOM 59, 34 (2007).

3. T.T. Chen and J.E. Dutrizac, Can. Metall. Q. 29, 27 (1990).

4. T.T. Chen and J.E. Dutrizac, Can. Metall. Q. 30, 173 (1991).

5. T.T. Chen and J.E. Dutrizac, Can. Metall. Q. 35, 337 (1996).

6. M.L. Free, Hydrometallurgy: Fundamentals and Applications (New York, NY: Wiley, 2013), pp. 229-231.

7. W. Zeng, S. Wang, and M.L. Free, Metall. Mater. Trans. B (2016). doi:10.1007/s11663-016-0736-4.

8. W. Zeng, M.L. Free, and S. Wang, J. Electrochem. Soc. 163, E14 (2016).

9. W. Zeng, M.L. Free, J. Werner, and S. Wang, J. Electrochem. Soc. 162, E338 (2015).

10. W. Zeng, S. Wang, and M.L. Free, J. Electrochem. Soc. 163, E111 (2016). 
11. W. Zeng, J. Werner, and M.L. Free, Hydrometallurgy 156, $232(2015)$

12. A. Eklund, D. Simonsson, F. Alavyoon, R. Karlsson, and F. Bark, Inst. Chem. Eng. Symp. Ser. 112, 47 (1989).

13. Y. Konishi, Y. Tanaka, Y. Kondo, and Y. Fukunaka, Electrochim. Acta 46, 681 (2001).

14. D. Ziegler and J.W. Evans, J. Electrochem. Soc. 133, 559 (1986).

15. S. Kawai and T. Miyazawa, Miner. Eng. 63, 81 (2014).

16. A. Kemminger and A. Ludwig, Proc. Eur. Metall. Conf. EMC 2, 795 (2013)

17. H. Hemmati, A. Mohebbi, A. Soltani, and S. Daneshpajouh, Hydrometallurgy 139, 54 (2013).

18. V.A. Ettel, A.S. Gendron, and B.V. Tilak, Metall. Mater. Trans. B 6, 31 (1975).

19. M.E. Schlesinger, M.J. King, K.C. Sole, and W.G. Davenport, Extractive Metallurgy of Copper, 5th ed. (Oxford: Elsevier, 2011), pp. 251-280.

20. C. Wenzl, A. Filzwieser, S. Konetschnik, and T.T. Chen, Honorary Symposium on Hydrometallurgy, Electrometal- lurgy and Materials Characterization (Hoboken, NJ: Wiley, 2012), pp. 63-76.

21. A. Filzwieser, I. Filzwieser, and S. Konetschnik, JOM 64, 1290 (2012).

22. M. Tabatabaian, COMSOL ${ }^{\circledR}$ for Engineers (Dulles, VA: Mercury Learning and Information, 2014).

23. J. Newman and K.E. Thomas-Alyea, Electrochemical Systems, 3rd ed. (Hoboken, NJ: Wiley, 2004), pp. 271-276.

24. Comsol Multiphysics User's Guide, version 4.3a, COMSOL (2012).

25. E. Mattsson and J. O'M Bockris, Trans. Faraday Soc. 55, 1586 (1958)

26. J.D. Anderson Jr., Computational Fluid Dynamics: The Basics with Applications (New York, NY: McGraw-Hill Inc, 1995), pp. 37-82.

27. D.C. Price and W.G. Davenport, Metall. Trans. B 11B, 159 (1980).

28. M.S. Moats, J.B. Hiskey, and D.W. Collins, Hydrometallurgy 56, 255 (2000). 